\title{
USING GENE EXPRESSION AND OTHER NEW RESEARCH TOOLS TO ENHANCE AND JUDGE POULTRY
}

\section{PRODUCTION}

\section{Y. Eid}

Department of Poultry Production, Faculty of Agriculture, University of Kafrelsheikh, 33516 Kafr El-Sheikh Egypt

No doubt that poultry industry significantly contributes to the human nutrition around the globe. This fast growing industry is facing a lot of challenges concerning the quantity and the quality of the product. Recently, epigenetic approach was introduced to the poultry researchers including In-ovo feeding and prenatal thermal manipulation in order to increase the poultry productivity. In 2004 the full chicken genome map already sequenced, and nowadays the genetic map for more than 100 species along with human is already known. Based on this knowledge a new research approaches which combine nutrition and genetic in one term "nutrigenomics" already appeared. Nutrigenomics aims to the study the effects of foods and/or feed ingredients on different genes expressions. Applying such approaches together with biochemical approach in poultry research may reveal a bitter understanding to the poultry performance under different circumstances and guarantee feasible and safer production beside good animal welfare. Introduction to such approaches and possible methods of application in poultry research will be discussed in details.

Issued by The Egyptian Society of Animal Production 